\title{
Genetic differentiation between natural populations of Drosophila subobscura in the Western Mediterranean Area with respect to chromosomal variation
}

\author{
A. PREVOSTI *, Rosa de FRUTOS **, G. AlONSO *, Amparo LATORRE **, \\ Maria MONCLUS * and Maria-José MARTINEZ ** \\ * Departamento de Genética, Facultad de Biologia, Universidad de Barcelona, \\ Barcelona-28, Spain \\ ** Departamento de Genética, Facultad de Ciencias Biológicas, Universidad de Valencia, \\ Burjasot (Valencia), Spain
}

\begin{abstract}
Summary
The chromosomal arrangement frequencies of 27 populations of Drosophila subobscura from the western Mediterranean region have been compared. To evaluate the relationships between these populations, factorial analysis of correspondences (BENZECRI, 1973) and a distance proposed by PrEvosTi (1974 a) have been used. The general clines present throughout the distribution of the species were also detected in the western Mediterranean area. Distinct chromosomal polymorphism was found in three areas : Tunisia, continental Europe and the whole of Sicily and Sardinia. Smaller islands were subject to stronger foreign influences. Iviza, Ponza and Ventotene showed small differences with the nearest continental populations. Ustica was rather similar to Sicily, its nearest major area ; however, Lipari, in spite of its vicinity to Sicily, showed greater similarity to the more distant continental Italian populations. The Corsican population seemed to be influenced by all its surrounding populations. The observed differences appear to be correctly interpreted as the consequence of adaptive selection (expressed in latitudinal clines) interacting with historical factors related to physiographical conditions which determine the degree of isolation between populations. Also, the size of the concerned regions seemed to be important : two of the three well differentiated areas were continental and the third included the two larger islands, Sicily and Sardinia. Corsica, next in size, showed a high frequency of a generally rare arrangement, $\mathrm{O}_{3+4}+17$; if genetic drift were a main factor in the differentiation of these populations, the reverse situation would be true.
\end{abstract}

Key words : Chromosomal polymorphism, Drosophila subobscura, geographical variation, isolation, migration.

\section{Résumé}

Variabilité génétique des populations naturelles de Drosophila subobscura du bassin méditerranéen occidental : étude des remaniements chromosomiques

Cet article porte sur une comparaison des fréquences des remaniements chromosomiques présents dans 27 populations de Drosophila subobscura du pourtour méditerranéen occidental. Les relations entre ces populations sont étudiées grâce à l'analyse factorielle des 
correspondances (BENZECRI, 1973) et à une mesure de distance proposée par PREvosti $(1974 \mathrm{a})$. Les clines généraux observés au niveau de la distribution globale de l'espèce se retrouvent dans cette aire méditerranéenne. Trois zones se distinguent vis-à-vis de ce polymorphisme chromosomique : la Tunisie, l'Europe continentale et l'ensemble "Sicile-Sardaigne ». Les îles plus petites sont soumises à des influences externes plus marquées. Ibiza, Ponza et Ventotene ne diffèrent que peu des régions continentales adjacentes. Ustica ressemble plutôt à la Sicile, sa proche voisine alors que Lipari qui est également située à proximité, se rapproche davantage des populations de l'Italie continentale. Quant à la Corse, elle est influencée, semble-t-il, par toutes les populations voisines. Les différences observées peuvent s'interpréter comme la conséquence d'une sélection adaptative (exprimée dans les clines latitudinaux) interagissant avec des facteurs historiques liés aux conditions physiographiques qui déterminent le degré d'isolement entre populations. De plus, la taille des régions concernées paraît importante à considérer : deux des trois zones bien différenciées sont continentales alors que la troisième regroupe les deux plus grandes îles, la Sicile et la Sardaigne. La Corse qui vient à la suite par sa dimension présente à une fréquence élevée un remaniement généralement rare ; le contraire eut été observé si la dérive avait été la principale cause de différenciation de ces populations.

Mots clés : Polymorphisme chromosomique, Drosophila subobscura, variation géographique, isolement, migration.

\section{Introduction}

Drosophila subobscura, a common species in a broad area of the Paleoarctic region, is found throughout Europe (with the exception of northern Scandinavia), North Africa and the Near East. The karyotype of the species has 6 pairs of chromosomes : five rods, all showing inversion polymorphism, and one dot.

Several authors have extensively studied inversion chromosomal polymorphism in the species in different areas of its distribution. A synthesis of the results obtained has been reported by KRIMBAS \& Loukas (1980). The importance of historical factors in the geographical distribution of this polymorphism has been discussed by Prevostr et al. (1975) and Prevostr (1979) who stated the problem of the influence of adaptation versus that of historical factors on the characteristics of this polymorphism.

The physiography of the western Mediterranean region studied in this paper is especially suited to a deeper investigation of this problem. Two continental areas, North Africa and southern Europe, are separated by the sea. There are two mountain barriers in the western Mediterranean region of southern Europe : the Pyrenees between the Iberian Peninsula and southern France, and the Alps between southern France and Italy. There are also numerous islands differing in size and at varying distances from the mainland.

\section{Material and methods}

A total of 27 populations from the western Mediterranean region has been analysed (fig. 1). Data on 13 of these populations have already been published by several 


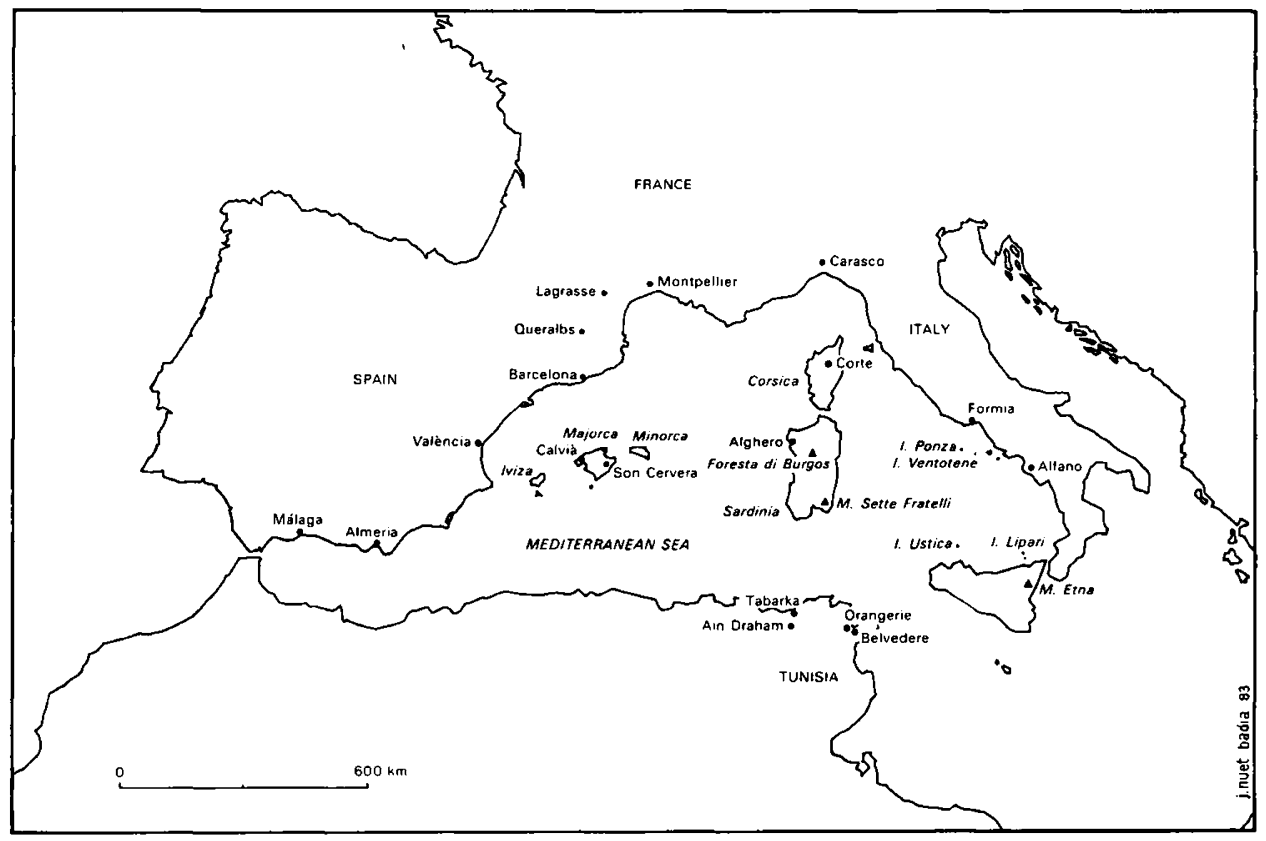

FIG. 1

Populations analysed.

Populations analysées.

authors : Spain (Prevosti, 1964 a, 1966, 1968 ; Frutos, 1972), France (Prevosti, 1964 b), Italy (Sperlich, 1961 ; KunZe-Muhl \& Sperlich, 1962 ; SPERlich \& KunzeMuhl, 1963) and Tunisia (JUNGEN, 1968). A newly collected sample of two other already published populations (Iviza in the Balearic Islands and Valencia in Spain) has been pooled with the old data since there were no statistically significant differences between the two samples. We also included unpublished data on 12 populations comprising continental Spain (Almería), continental France (Montpellier), Corsica (Corte), continental Italy (Carasco and Alfano), Sardinia (Alghero, Foresta di Burgos and Sette Fratelli), Sicily (Etna) and the Balearic Islands (one population from Minorca ; Calvià and Son Cervera from Majorca).

Factorial analysis of correspondences (FAC) (BENZECRI, 1973) was used to evaluate the general relationships between the studied populations. The formula proposed by Prevosti (1974 a) was employed to measure the overall differences between pairs of populations :

$$
\mathrm{D}=\frac{1}{2 \mathrm{r}} \sum_{\mathrm{j}=1}^{\mathrm{r}} \sum_{\mathrm{k}=1}^{\mathrm{s}_{\mathrm{j}}}\left|\mathrm{p}_{1 \mathrm{jk}}-\mathrm{p}_{2 \mathrm{jk}}\right|
$$

where $\mathrm{r}$ is the number of polymorphic chromosomes ( 5 in $D$. subobscura); $\mathrm{S}_{\mathrm{j}}$ is the number of different arrangements in the chromosome $j ; p_{1 j k}$ and $p_{2 j k}$ are the fre- 
quencies of the arrangement $\mathrm{k}$ of the chromosome $\mathrm{j}$ in populations 1 and 2 , respectively.

The degree of polymorphism was expressed by mean heterozygosity and Carson's index of free recombination (CARSON, 1955). Besides considering heterozygote frequency, Carson's index takes into account the length of chromosomal fragments present in heterozygosity.

\section{Results}

\section{A. Latitudinal clines}

The frequencies of the arrangements in all the analysed populations are shown in table 1.

The latitudinal clines generally present throughout the distribution of the species were also detected in the western Mediterranean area. The arrangements $A_{\text {st }}, J_{\text {st }}, U_{\text {st }}$ and $E_{s t}$ showed a decreasing frequency southwards as in other areas. The highest frequencies were observed in the French populations and in Carasco (northern Italy). On the Mediterranean shore of the Iberian Peninsula, their frequency decreased southwards, and in Italy the same trend was found, but it was less evident. Tunisian populations showed very low frequencies of these arrangements. $U_{\text {st }}$ had much lower frequencies than the other standard arrangements in all the western Mediterranean populations and was not detected in the Tunisian populations or in Alfano (southern Italy). The distribution of $\mathrm{O}_{\mathrm{st}}$ was a bit different. Its frequency was high in France and in the Spanish populations near the Pyrenees (Queralbs and Barcelona), but was low in northern Italy (Carasco); it decreased southwards much more in Italy than in Spain.

Complementary to the southward decrease of $\mathbf{J}_{\mathrm{st}}$ was the increase of $\mathbf{J}_{1}$ in the same direction. The variation of $A_{2}$ was similar to that of $J_{1}$, with the exception of the Tunisian populations where the high frequency of the endemic arrangements $A_{2+6}$ and $\mathrm{A}_{2+3+5+7}$ introduced a differential element. Populations from Italy and Spain differed in chromosomes $\mathrm{U}, \mathrm{E}$ and $\mathrm{O}$. Whereas $\mathrm{U}_{1+2+8}$ showed a gradual and sharp increase southwards in Spain, in Italy this increase was slighter and less regular due to the presence of high frequencies of $U_{1+2+3}, U_{1+2+4}$ and $U_{1+2+6}$. The very high frequencies of $\mathrm{U}_{1+2+8}$ in Sicily and Sardinia must be considered not only in relation to the southern position of these islands but also to their isolation.

Some of the differences between Spanish and Italian populations in the western Mediterranean areas reveal that W-E clines are present in the whole Mediterranean region. This is the case of the increasing eastward frequency of $A_{1}, U_{1+2+6}$, $\mathrm{E}_{1+2+9}, \mathrm{E}_{8}$ and perhaps of $\mathrm{O}_{3+4+2}$.

\section{B. Regional differentiation}

Figure 2 shows factorial analysis of correspondences for each chromosome and for all the chromosomes taken together. The diagrams of figure 2 represent only the 


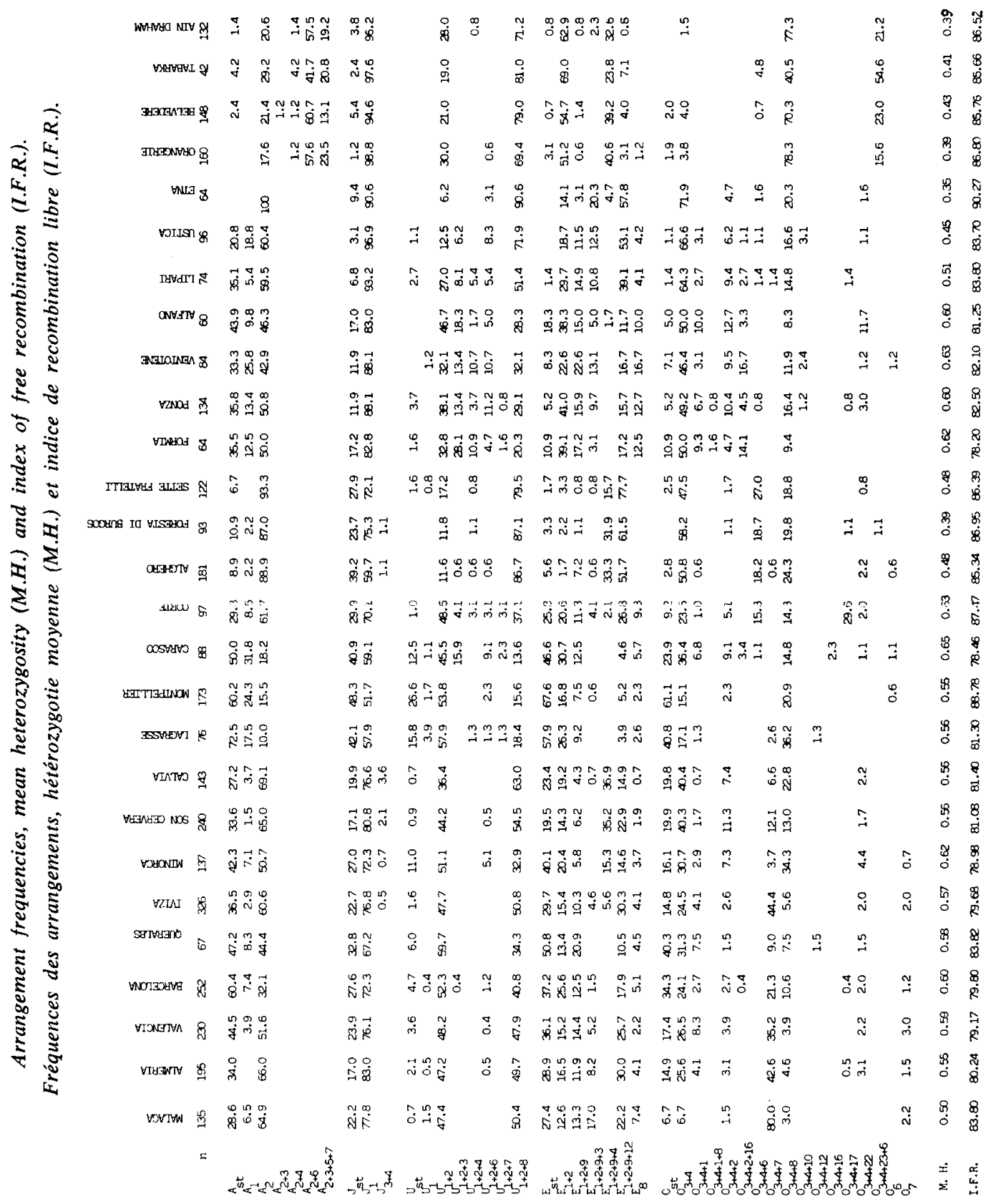


two main components of population differentiation. The percentages of variation corresponding to these components for axis 1 and axis 2, respectively, were : chromosome A, 76.24 and 17.31; chromosome J, 84.66 and 15.34; chromosome U, 57.44 and 22.66; chromosome E, 76.24 and 17.31 ; chromosome $0,31.53$ and 21.48 ; all the chromosomes, 32.88 and 18.28. This could cause some distortion of the actual relative positions of the populations. To avoid this possibility, the distances between the populations given on table 2 were based on differences in the frequency of chromosomal arrangement and calculated with the formula proposed by Prevosti (1974 a).

TABLE 2

Distances between populations.

Distances entre populations.

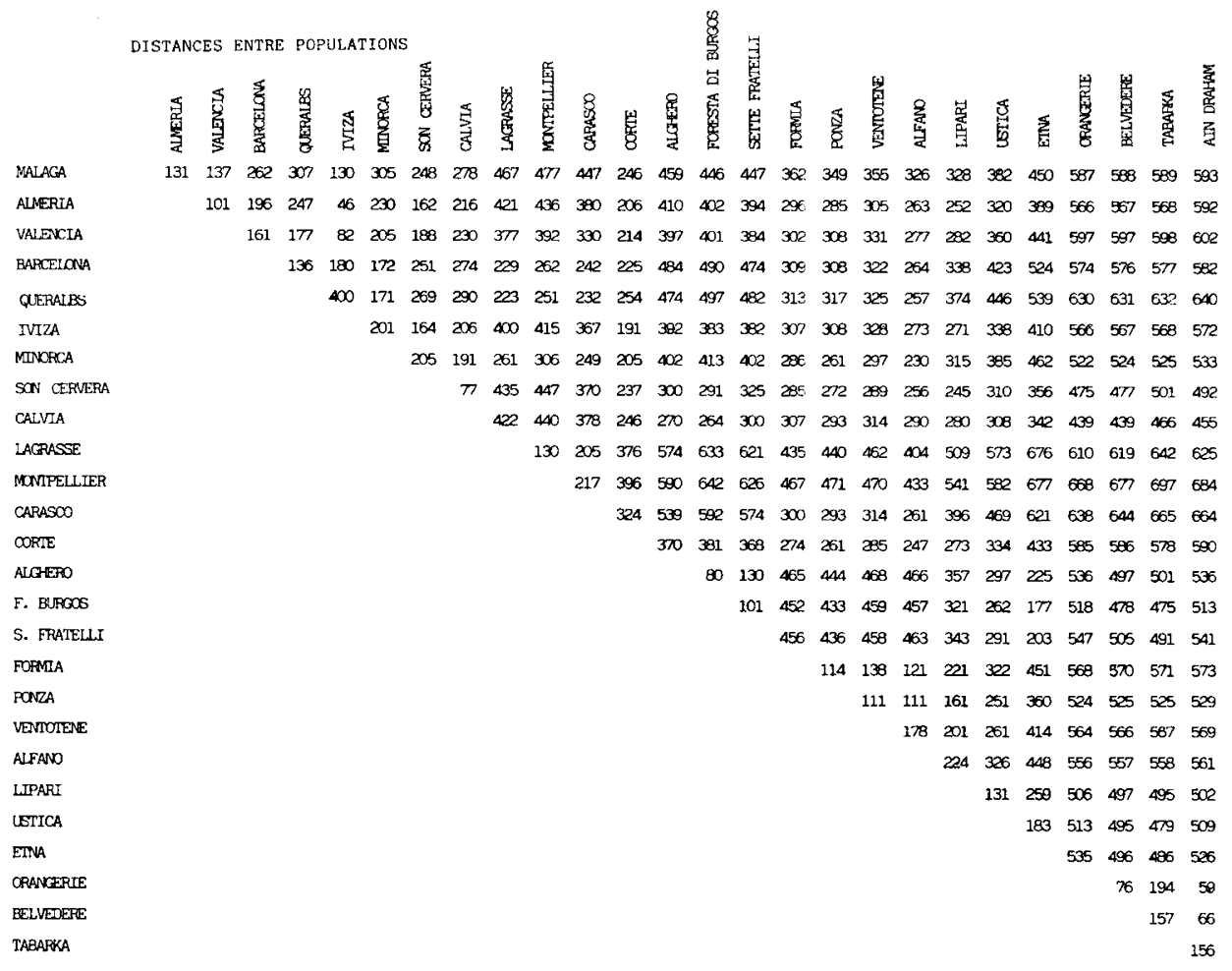

\section{Mainland populations}

Table 2 and figure 2 both show that the Tunisian populations were the most differentiated. The direction of greatest differentiation on figure $2 \mathrm{f}$ is the vertical axis, and the North African populations diverge from all the other populations in relation to this axis. The A chromosome had the greatest influence on this general differen- 


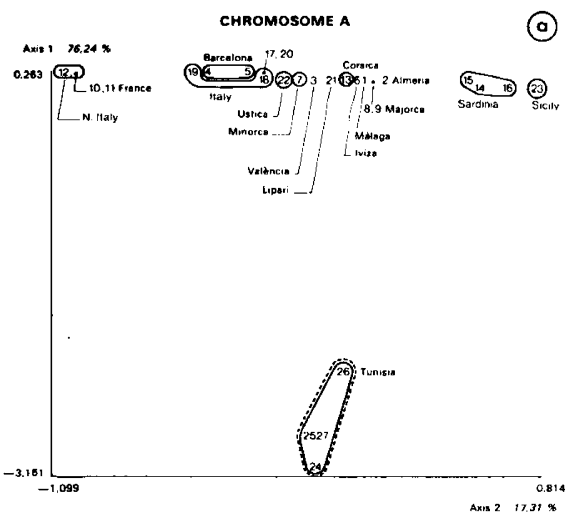

CHคOMOSOME U

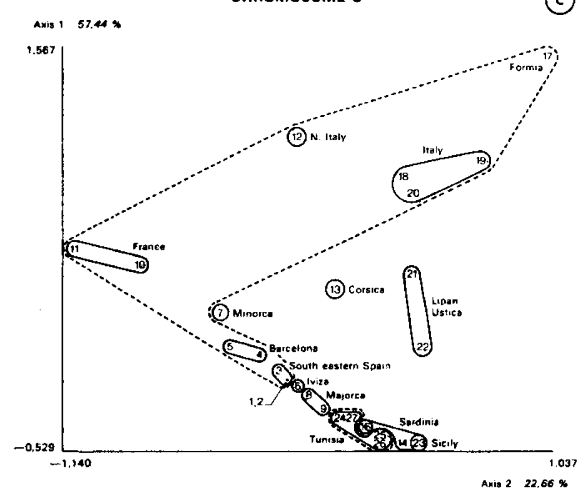

CHROMOSOME O

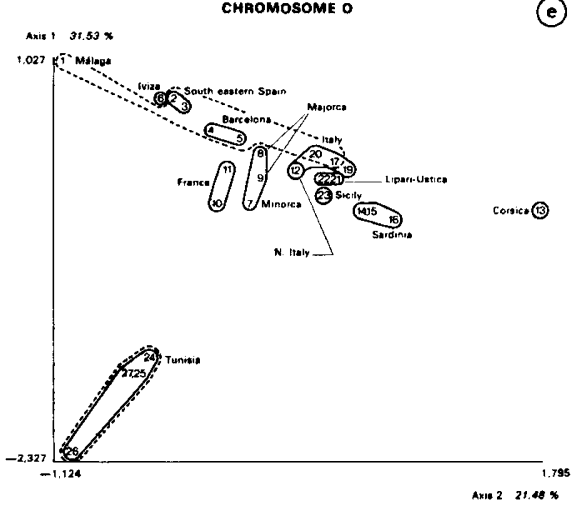

CHROMOSOME J

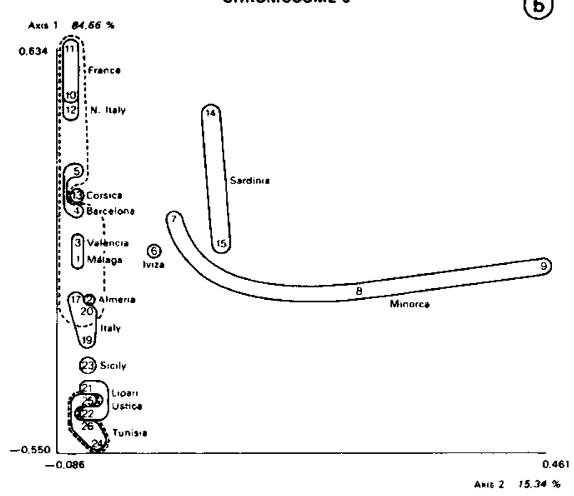

CHROMOSOME E
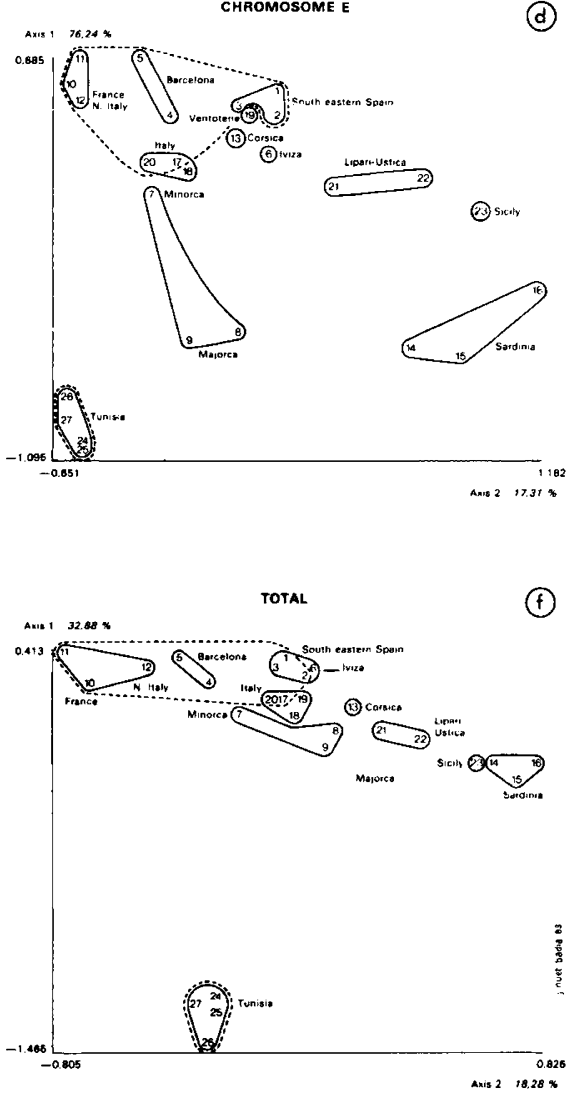

Fig. 2

Diagrams obtained with factorial analysis of correspondences.

Axes 1 and 2 indicate the first two main components; the percentages of variability accounting for each of these components are indicated.

Diagrammes obtenus par l'analyse factorielle des correspondances.

Les axes 1 et 2 figurent les deux premières composantes les plus importantes; le pourcentage de variabilité lié à chacune d'elles est indiqué.

1. Malaga; 2. Almeria; 3. Valencia; 4. Barcelona; 5. Queralbs; 6. Iviza; 7. Minorca;

8. Son Cervera ; 9. Calvia; 10. Lagrasse; 11. Montpellier; 12. Carasco ; 13. Corte;

14. Alghero; 15. Foresta di Burgos; 16. Sette Fratelli; 17. Formia; 18. Ponza;

19. Ventotene; 20. Alfano; 21. Lipari; 22. Ustica; 23. Etna; 24. Orangerie; 25. Belvedere;

26. Tabarka; 27. Ain Draham. 
tiation (fig. 2 a) due to the presence of endemic arrangements like $A_{2+6}$ and $\mathrm{A}_{2+3+5+7}$ with high frequencies in North Africa (table 1). Figure $2 \mathrm{e}$ shows that chromosome $\mathrm{O}$ also contributed strongly to the separation of the Tunisian populations. This is explained by the presence of the endemic arrangement $\mathrm{O}_{3+4+2+6}$ and the frequency of $\mathrm{O}_{3+4+8}$ which was much higher than in the other populations. In the diagrams of chromosomes $\mathbf{J}$ and $\mathbf{U}$ (fig. $2 \mathrm{~b}$ and $\mathrm{c}$ ), the Tunisian populations are also situated at one end of axis 1 , but there is no discontinuity between these populations. Actually, in these diagrams the populations are usually arranged along axis 1 , according to the southward clines of increase of $\mathrm{J}_{1}$ and $\mathrm{U}_{1+2+8}$ frequencies, respectively. On figure $2 \mathrm{~d}$, the Tunisian populations are also at one end of axis 1, expressing their high frequency of $E_{s t}, E_{8}$ and $E_{1+2+9}$. The main component of between-population differences in the $\mathrm{E}$ chromosome also included, to some degree, the effect of latitudinal clines since $\mathrm{E}_{\mathrm{st}}$ affected this component.

The populations from continental Europe (fig. 2 f) are at the opposite end of axis 1 from the Tunisian ones. This means that maximal differentiation within the western Mediterranean populations occurred in these regions. On the other hand, differences within the continental European area are expressed by the direction of axis 2, and they are arranged along this axis according to latitude. At one end of the axis are the French populations and Carasco (northern Italy), followed by populations from the northern Mediterranean shore in Spain and lastly, a bit separated and towards axis 1, the populations from southern Spain and Italy.

Considering the chromosomes separately, the populations from continental Europe appear more scattered; more similarity is found in the diagram of chromosome E. Also, population distribution along axis 2 is maintained; more southern populations have higher values on this axis, although those from southern Italy are closer to populations from northern than from southern Spain. The populations from southern Italy and Spain are also slightly shifted in the direction of axis 1. The decrease of $E_{s t}$ southwards and the increase of $E_{1+2+9+12}$ and $E_{1+2+9+3}$ in the same direction account for the variation along axis 2 . The higher frequencies of $E_{8}$ and $E_{+1+2+9}$ in Italy account for the differences between the populations from southern Italy and southern Spain. The diagram of chromosome $\mathrm{J}$ also shows clustering of the populations from continental Europe. However, the populations in this diagram are arranged according to latitude along the axis of main differentiation (axis 1). The distributions of the other chromosomes show a greater complexity. Populations with chromosome $\mathrm{A}$ are also placed along axis 2 and, as with the $\mathrm{E}$ chromosome, increasing values along this axis tend to be arranged according to decreasing latitude. However, populations from southern Italy and southern Spain do not fit into this order due to the higher frequency of $A_{2}$ in Spain and of $A_{1}$ in Italy. Also, some populations from the islands are interspersed within the continental ones. Starting from the position of French populations at the lowest values of axis 1 , the $U$ chromosome values of the Italian and Iberian populations are situated on divergent lines. A decrease of $\mathbf{U}_{\mathbf{s t}}$ and $\mathrm{U}_{1+2}$ and an increase of $\mathrm{U}_{1+2+8}$ is found along the line corresponding to the Iberian populations. The divergent position of the Italian populations is mainly due to the presence of $U_{1+2+3}, U_{1+2+4}$ and $U_{1+2+7}$ arrangements and to the higher frequency of $\mathrm{U}_{1+2+6}$. The greater complexity of polymorphism in this Italian chromosome explains the irregularities observed in the distribution of these populations in the diagram. Actually, this complexity is probably the main difference between the polymorphism of Italian and Iberian populations. In the diagram of the $\mathrm{O}$ chro- 
mosome, the French populations are closest to the Tunisian ones due to $\mathrm{O}_{3+4+8}$. This arrangement is dominant in North Africa and also has a high frequency in France. The other populations from continental Europe are distributed along a straight line beginning with Malaga placed at minimal values of axis 2 and maximal values of axis 1. The Spanish populations are distributed on this line according to latitude, and the Italian ones are clustered at the other end of the line. The situation of the Spanish populations on this line depends on $\mathrm{O}_{\text {st }}$ frequencies, which are maximal in the north, and on the increase of $\mathrm{O}_{3+4+7}$ southwards. In Italy, $\mathrm{O}_{3+4+7}$ is almost lacking and $\mathrm{O}_{\text {st }}$ is replaced by $\mathrm{O}_{3+4}$ southwards and in the second term by $\mathrm{O}_{3+4+1}$, $\mathrm{O}_{3+4+2}$ and $\mathrm{O}_{3+4+16}$; the frequency of these arrangements explains the position of the Italian populations in this diagram.

\section{Island populations}

Perhaps the most interesting feature of this paper is the analysis of chromosomal polymorphism in the islands. The general FAC diagram shows that the island populations are more similar to those of continental Europe than to the Tunisian populations. A second observation is that the islands more differentiated from continental European populations, Sardinia and Sicily, are close together and shifted mainly in the direction of axis 2. On the other hand, the differences between European and North African populations are mainly expressed along axis 1 . Thus the differentiation of these islands is not particularly influenced by their proximity to Tunisia. The high frequencies of $A_{2}, U_{1+2+8}$ and $E_{1+2+9+12}$ explain the differentiation of these islands. The high frequency of $\mathrm{E}_{1+2+9+4}$ in Sardinia and a rather high frequency of $\mathrm{O}_{3+4+8}$ in both islands are the only resemblances to the Tunisian populations.

Some islands situated near the mainland show very small differences with the nearest continental populations. This is the case of Ponza and Ventotene which are very similar to the mainland population of Formia. Also, Iviza, the smallest of the Balearic Islands and the nearest to the continent, shows very small differences with Valencia and Almeria. However, in terms of genetic distance (table 2), the population from Lipari island shows greater similarity to the more distant continental Italian populations than to Sicily. On the other hand, the genetic disance between Ustica and Sicily is much less than between Ustica and the continental populations.

The differences between Corsica and Sardinia are considerable, in spite of the close vicinity of these islands. Populations from Sardinia show more southern features : the frequencies of the standard arrangements are lower, and those of typically southern arrangements like $\mathrm{U}_{1+2+8}, \mathrm{E}_{1+2+9+12}$ and $\mathrm{O}_{3+4}$ are much higher. Also, in Corsica $\mathrm{O}_{3+4+17}$ has a frequency of 29.6 p. 100 but in Sardinia it is only present in one population (Foresta di Burgos) with a frequency of 1.1 p. 100 . However, there is a point of similarity between the two islands : in all the western Mediterranean area, the only populations having a high frequency of $\mathrm{O}_{3+4+6}$ are those from Sardinia and Corsica. In spite of its pecularities, the Corsican population is fairly similar to those from continental Italy and southern Spain.

The populations from the Balearic Islands are characterized by their dispersed position in the general FAC diagram; only those from Majorca are closely located. The populations from each of these islands resemble different populations, producing a distortion of their position in the diagrams which does not fit completely with the genetic distances between them. 
The distribution of the Balearic Islands in the diagram of the $\mathbf{E}$ chromosome fits the best with the general one. The vicinity of Majorcan populations to Tunisian ones is strongly influenced by the polymorphism of this chromosome, especially by the frequency of $E_{1+2+9+4}$. The frequency of $E_{1+2+9+4}$ in the Majorcan populations approximates that in the Sardinian populations. The frequencies of $E_{s t}, E_{1+2}, E_{1+2+9}$, $\mathrm{E}_{1+2+9+3}$ and $\mathrm{E}_{1+2+9+12}$ in Iviza considerably resemble those of Almería and Valencia. The A chromosome of the Balearic Islands shows a scattered distribution. Majorca and Iviza are rather similar and situated in the vicinity of populations from southern Spain due to their frequencies of $A_{s t}$ and $A_{2}$; Minorca is more similar to populations from Catalonia and Valencia. In the $\mathbf{J}$ chromosome diagram, Sardinia and the Balearic Islands are outside the line expressing the latitudinal cline of $\mathbf{J}_{\mathbf{s t}}$ and $J_{1}$ arrangements. Axis 2 of this diagram corresponds to the variation of $J_{3+4}$, a rare arrangement in the western Mediterranean region and only found on these islands. Even considering that axis 2 is represented in this diagram in large scale, the effect of $\mathrm{J}_{3+4}$ seems to be exaggerated since the highest frequency of this arrangement is only 3.6 p. 100 in Calvià (Majorca). In the $U$ chromosome diagram, the Balearic Islands, Sardinia and Sicily appear on one line of populations according to the cline of the arrangements $U_{s t}, U_{1+2}$ and $U_{1+2+8}$; Sardinia and Sicily are at one end of this line due to their high frequency of $U_{1+2+8}$. The Balearic Islands are scattered as in the other diagrams : Iviza and Majorca resemble those of southern Spain and even Tunisia; Minorca approximates French populations even more than those from northern Spain.

The characteristic scattering of the position of the Balearic Islands also appears in the diagram of the $\mathrm{O}$ chromosome. Iviza stays very near to the populations of southern Spain and far from those of Majorca and Minorca; the reason for this is the frequency of $\mathrm{O}_{\text {st }}$ and $\mathrm{O}_{3+4}$ and the high frequency of $\mathrm{O}_{3+4+7}$ in Iviza. Besides having a higher frequency of $\mathrm{O}_{\text {st }}$ and $\mathrm{O}_{3+4}$, Majorca and Minorca also have a high frequency of $\mathrm{O}_{3+4+8}$; this shifts the position of the populations of these islands near to those of France and Italy.

\section{E. Mean heterozygosity and index of free recombination (table 1)}

The greatest polymorphism is found in continental Italy, including the small islands of Ponza and Ventotene, and in the islands of Corsica and Minorca. These populations show the highest values of mean heterozygosity (over 0.600). Thus, free recombination reaches its lowest values in these areas, Ponza, Ventotene and Alfano in southern Italy excepted.

In contrast with the high polymorphism of populations from continental Italy and the island of Corsica, the lowest values are found in the nearby islands of Sardinia and Sicily. Polymorphism is also low in Tunisia. High I.F.R. values correspond to low values of mean heterozygosity in these populations. The highest value of this index is 90 in Sicily, where mean heterozygosity is minimal.

In the islands of Lipari and Ustica, the degree of polymorphism is intermediate between that of continental Italy and Sardinia and Sicily. This agrees with the situation of these islands in the FAC diagrams.

The greatest polymorphism in the Mediterranean area of the Iberian Peninsula 
is found in the north and decreases gradually southwards. There is also less polymorphism in the Mediterranean populations from France and the Balearic Islands, with the exception of Minorca.

\section{Discussion}

Three main areas have been distinguished in the western Mediterranean area according to the characteristics of chromosomal polymorphism in $D$. subobscura populations. These areas are Tunisia (which seems to be representative of North Africa in general according to data on the non-Mediterranean populations of Morocco ; Prevosti, 1974 b), continental Europe, and the whole of Sicily and Sardinia. The population of the island of Corsica, although presenting some peculiarities like a high frequency of $\mathrm{O}_{3+4+17}$, is generally at a small genetic distance from most of the other populations, Tunisia excepted. The population of this island seems to be more influenced by all its surrounding populations.

Two important factors may explain the differentiation of the three regions. First, they are isolated from each other. As pointed out by Prevosti et al. (1975), geographical barriers like sea arms or mountain ranges limit migration between populations and are important factors in the differentiation of chromosomal polymorphism in D. subobscura populations. Genetic distance, based on the frequency of chromosomal arrangements, is much greater between populations separated by a barrier than between populations of equal geographical distance but with no barrier between them. Second, differentiation of chromosomal polymorphism depends on the size of the regions concerned. The importance of this second factor has been discussed by PREvosTr et al. (1975) but appears very clearly in the western Mediterranean data. Two of the three main areas of differentiation are continental and the third is formed by the two larger islands, Sicily and Sardinia. Corsica is next in size and is noteworthy due to its high frequency of $\mathrm{O}_{3+4+17}$. If genetic drifts were a main factor in the differentiation of these populations, the situation would be exactly the reverse, and the populations from small islands like Lipari, Ustica and the Balearics would show more differentiation .

The observed differences seem to be correctly interpreted as a consequence of adaptive selection (expressed in latitudinal clines) interacting with historical factors related to physiographical conditions which determine the degree of isolation of populations. The larger the separated areas, the greater would be the differentiation effect of barriers imposing an equal degree of isolation. The important parameter of differentiation is the coefficient of migration and the number of migrants passing a barrier being equal, this coefficient would be smaller the larger the areas receiving the migrants. Also, if the frequency of migrants is low, the new arrangements occurring in the populations might often be lost, etiher by chance or because they are carriers of gene complexes not coadapted with the gene pool of the receiving population. As a consequence of this lack of coadaptation, the progenies of crosses between migrant and autochthonous individuals would be less fit to survive, and the newly introduced arrangements would have low probability of being maintained in the population. This interpretation is supported by observations carried out in the Canary Islands (PRE- 
vostr, unpublished data) where arrangements typical of continental Africa (like $\mathrm{A}_{2+3+5+7}$ which never rise to substantial frequencies) are sporadically found.

If genetic drift were an important factor influencing the characteristics of chromosomal polymorphism in D. subobscura, we would also expect that variability in chromosomal arrangement would be low in small islands. This should be expressed by the values of mean heterozygosity, but these values are low only in the larger islands such as Sardinia and especially Sicily. The characteristics of chromosomal polymorphism in these islands have been discussed by Prevosti et al. (1975) on the basis of their genetic distance from other populations. It was found that the populations nearest to Sicily were those from the Canary Islands and, reciprocally, the populations closest to those of the Canary Islands, were those from Sicily followed by those from Sardinia. Chromosomal polymorphism in populations from the Canary Islands seems to be in a rather early stage of development. The similarity of Sicily and Sardinia indicates that in these islands some old features may also have been retained due to isolation.

The greater variability of the smaller islands is a consequence of the relatively greater frequency of migrants from other areas and of the more successful establishment of the arrangements brought by the migrants. A greater variety of influences was detected in Corsica, perhaps because of its position. Besides the general influence of continental European populations, a specific relationship with Italian populations is expressed by the presence of $U_{1+2+3}, U_{1+2+4}$ and $U_{1+2+7}$ and with Sardinia and Tunisia by the presence of $\mathrm{O}_{3+4+8}$ and $\mathrm{E}_{1+2+9+4}$, respectively. A high frequency of $\mathrm{O}_{3+4+17}$ is only found in some Anatolian populations in the eastern Mediterranean area. These various influences explain the high degree of polymorphism in Corsica.

In the Balearic Islands, $\mathbf{J}_{3+4}$ (also observed only in Sardinia in the western Mediterranean area) was found. This arrangement, typical of eastern Mediterranean regions, reaches its highest value in Israel (GoldschmidT, 1956) and Crete (KRIMBas \& Alezivos, 1973) and substantial frequencies in Greece and Anatolia. It is difficult to explain the presence of this arrangement in the Balearic Islands, unless carried there by man. Communication among the Balearics and Sardinia with the eastern Mediterranean region is old. In any case, the establishment of this arrangement in the islands, and not in continental European populations, is another fact pointing to the easier establishment of foreign arrangements in the islands. Communication with the eastern Mediterranean was also intensive in several continental areas such as the Iberian Peninsula, and $\mathbf{J}_{3+4}$ has not been found there. Another foreign influence in the Balearic Islands is the high frequency of $\mathrm{E}_{1+2+9+4}$, especially in Majorca. It could have arrived from Sardinia or directly from North Africa. Transport is also a plausible explanation due to the distance from possible areas of origin. Rather important differences are also observed within the Balearic Islands. Iviza is very similar to continental Iberian populations, whereas the influence of Iberian populations seems to be much weaker in Majorca and Minorca. $\mathrm{O}_{3+4+7}$, typical of the Iberian Peninsula, shows a high frequency in Iviza, but is low in the other islands. $E_{1+2+9+3}$, not rare on the Peninsula, shows an appreciable frequency in Iviza but has been found only once in the other islands. On the other hand, $\mathrm{O}_{3+4+2}$, and especially $\mathrm{O}_{3+4+8}$, have higher frequencies in Majorca and Minorca than on the Spanish mainland. The high frequencies of $\mathrm{O}_{3+4+2}$ and $\mathrm{O}_{3+4+8}$ in these islands are perhaps better interpreted as a consequence of isolation rather than of a foreign influence. The differences among 
the islands of the Archipelago could also be generally interpreted this way. These differences are greater than in the Canary Islands where the arrangement distances are usually less than 100, except for those of Hierro Island (the greatest distance between Vilaflor in Tenerife and Pinar in Hierro amounts to 116). However, the uniformity of the Canarian populations is mainly due to monomorphism in the $A, J$ and $O$ chromosomes. In fact, there are differences among the islands as to arrangements of the $U$ and, especially the $E$ chromosome which are polymorphic Thus, in both archipelagos polymorphism tends to differentiate in the different islands, probably due to isolation, although in the Canary Islands only polymorphic chromosomes can differentiate. This monomorphism of Canary Island populations, interpreted as a primitive feature (Prevosti, 1971), has not been observed at all in Balearic Island populations.

Continental European populations show greater frequencies of the standard arrangements northwards, fitting with the general latitudinal clines found in these arrangements. Accordingly, the characteristically southern arrangements show higher frequencies in the southern populations. On the other hand, French and Italian populations are distinguishable within these populations because of the high frequency of $\mathrm{O}_{3+4 \dashv-8}$ in France (a general feature in other French populations) and the polymorphism of the $U$ chromosome in Italy (a general characteristic of Italian populations).

The populations from Spain and Italy have the above-mentioned latitudinal clines in common with all of Europe in general. They are rather different in other aspects : the polymorphism of the $\mathrm{O}$ and $\mathrm{U}$ chromosomes is richer in Italy, and the high frequency in Spain of the $\mathrm{O}_{3+t+7}$ arrangement practically lacking in Italy.

Received September 13, 1983.

Accepted December 7, 1983.

\section{References}

BenzeCri J.P., 1973. L'analyse des données. II. - L'analyse des correspondances, 619 pp., Dunod, Paris.

Carson H.L., 1955. The genetic characteristics of marginal populations of Drosophila. Cold Spring Harbor Symp. Quant. Biol., 20, 276-287.

Frutos R., 1972. Contribution to the study of chromosomal polymorphism in the Spanish populations of Drosophila subobscura. Genet. Iber., 24, 123-140.

GoldschmidT E., 1956. Chromosomal polymorphism in a population of Drosophila subobscura from Israel. J. Genet., 54, 475-496.

JUNGeN H.E., 1968. Inversionspolymorphismus in Tunesiscien Populationen von Drosophila subobscura Collins. Archiv Julius Klaus Stift., 43, 3-55.

Krimbas C.B., Alezivos V., 1973. The genetics of Drosophila subobscura populations. IV. - Further data on inversion polymorphism in Greece. Evidence of microdifferentiation. Egypt. J. Genet. Cytol., 2, 121-132.

Krimbas C.B., Loukas M., 1980. The inversion polymorphism of Drosophila subobscura. In : Hecht M.T., Steere W.C., Wallace B. (ed.), Evolutionary Biology, 12, 163-234, Plenum Publishing Corporation, New York and London. 
Kunze-Muhl E., SPerlich D., 1962. Vergleichende Untersuchungen über den chromosomalen Strukturpolymorphismus in Inseln und Festland-Populationen von Drosophila subobscura. Z. Vererbungsl., 93, 237-248.

Prevosti A., 1964 a. Chromosomal polymorphism in Western Mediterranean populations of Drosophila subobscura. Genet. Res., 5, 27-38.

Prevostr A., 1964 b. Tipos cromosómicos de Drosophila subobscura en una poblacion de Lagrasse (Francia). Genet. Iber., 16, 1-19.

Prevosti A., 1966. Chromosomal polymorphism in Western Mediterranean populations of Drosophila subobscura. Genet. Res., 7, 149-158.

Prevosti A., 1968. Efecto de la cordillera pirenaica sobe la distribución geográfica de las ordenaciones cromosómicas de Drosophila subobscura. Pirineos, 79-80, 221-228.

Prevostr A., 1971. Chromosomal polymorphism in Drosophila subobscura Coll. from the Canary Islands. Genet. Iber., 23, 69-84.

Prevosti A., 1974 a. La distancia genética entre poblaciones. Miscelánea Alcobé, 109-118, Universidad de Barcelona.

Prevosti A., 1974 b. Chromosomal inversion polymorphism in the southwestern range of Drosophila subobscura distribution area. Genetica, 45, 111-124.

Prevosti A., Ocaña J., Alonso G., 1975. Distances between populations of Drosophila subobscura based on chromosomal arrangement frequencies. Theor. Appl. Genet., 45, 231-241.

Prevosti A., 1979. Polimorfismo cromosómico y Evolución in "Evolución» Libros de Investigación y Ciencia (Scientific American), 85-100. Labor, S.A. Barcelona.

SPERLich D., 1961. Untersuchungen über den chromosomalen Polymorphismus einer Populatino von Drosophila subobscura auf den Liparischen Inseln. Z. Vererbungsl., 92, 74-84.

SPerlich D., Kunze-Muhl E., 1963. Der chromosomale Strukturpolymorphismus einer Population von Drosophila subobscura auf der Inseln Ustica im Vergleich mit anderen Inseln und Festland standorten. Z. Vererbungsl., 94, 94-100. 